grouped spherically. Owing to the fineness of the tablets and the capillary attraction, it is difficult to remove the impure motherliquor sufficiently from the crystals by means of a centrifugal machine, and even with a hydraulic press high purity cannot be obtained, together with a large yield. It is different with the crystals of anhydrous grape sugar. They are of a prismatic shape, and form loose aggregations from which the syrup can be easily removed by centrifugal force, and which lend themselves to a treatment of draining and washing very similar to that of cane sugar. Under these circumstances it is possible to produce a grape sugar which compares in purity with block and granulated cane sugar. A num. ber of applications for such an article readily suggest themselves. The confectioner, the druggist, the manufacturer of condensed milk may use it. In the preparation of certain wines it can safely take the place of cane sugar; but its principal use ought to be in the kitchen for all those preparations where utmost sweetness is not sought for. It is not so well suited for sweetening tea or coffee, though it does not quite so unfavorably compare with cane sugar as the books will have it. To obtain a moderate sweetness, equal to that produced by a given amount of cane sugar, it is not necessary to take $2 \frac{1}{2}$ or 3 times as much as cane sugar, but only about $1 \frac{2}{3}$ times the quantity; at least I have found it so, and some of $m y$ friends also.

\title{
V. THE WATER SUPPLY OF THE CITY OF NEW YORK.
}

\section{By E. Waller, Ph. D.}

I desire, in the first place, to present the results of complete analyses of the Croton water made at different times. The various denominations of salts quoted have been given in order to literally quote the different analysts. For the three first, double columns are given, representing the results in grains per English (Imperial) gallon of 70,000 grains, and also in grains per United States gallon of 58,318 grains, the first columns in each case being the form in which the analysts have recorded their results, to judge from the context. In Nos. 4 and 5, the magnesium and calciun bicarbonate have been calculated back to mono-carbonates, and the results given in brackets. Another table of the same results, calculated to parts per 100,000 , is appended. 
There is probably less difference in the results than the tigures would seem to indicate, the mode of stating the results in the earlier analyses rather suggesting different methods of conducting the examination, and calculating the results to those at present in use.

Next, permit me to call your attention to a chart showing graphically the variations found in the constitution of the Croton water by Dr. C. F. Chandler during the summer months of 1867 and 1868, representing some fifty examinations, and $\mathrm{my}$ own results, made in a similar manner every week, from the latter part of $18 \%$ to the middle of 1879 , representing about 350 examinations. The average results may be thus stated:

Average of results of tests made on Croton water Parts per $100,000):$

\begin{tabular}{|c|c|c|c|c|c|c|}
\hline & & $\begin{array}{l}\text { Nineral } \\
\text { matter: }\end{array}$ & $\begin{array}{l}\text { urg and } \\
\text { vointile. }\end{array}$ & $\begin{array}{l}\text { Total } \\
\text { otidids. }\end{array}$ & Hardness. & $\begin{array}{l}\text { xnabser: } \\
\text { bed from } \\
\text { Permant. } \\
\text { ginate. }\end{array}$ \\
\hline Summer of & 1867 & 0.72 & 1.12 & 7.84 & 4.32 & 0.181 \\
\hline 6 & 1868 & 5.66 & $1.9 \%$ & 8.63 & & 0.168 \\
\hline Last 2 mos. & $18 \% 2$ & 7.48 & 0.44 & 7.92 & 3.553 & 0.131 \\
\hline Ycar & $18 \% 3$ & 6.23 & 1.59 & 7.82 & 3.395 & 0.135 \\
\hline. & 1874 & 5.83 & 1.76 & $\hat{1.59}$ & 3.332 & 0.166 \\
\hline$\therefore$ & 1875 & 0.656 & 1.835 & 3.401 & 3.293 & 0.211 \\
\hline. & $18 \% 6$ & 5.416 & 1.082 & i.098 & 3.159 & 0.185 \\
\hline ." & $18 \%$ & 5.603 & 1.823 & $\lceil .426$ & 3.260 & 0.253 \\
\hline$" 6$ & $18: 8$ & 5.299 & 1.904 & 7.203 & 2.846 & 0.183 \\
\hline First 5 mos. & $18 \%$ & 5.424 & 0.912 & 6.336 & 2.811 & $0.0 \% 2$ \\
\hline $\begin{array}{c}\text { Average fro } \\
1872, \text { to } \mathrm{I} \\
\text { inclusive }\end{array}$ & $\begin{array}{l}\mathrm{No} \\
18\end{array}$ & 5.802 & 1.678 & $\% .380$ & 3.210 & 0.180 \\
\hline
\end{tabular}

The "Total solids" were determined by weighing the residue obtained by evaporating a measured quantity; the "Organic and Volatile" by igniting this residue, moistening with carbonic acid water, drying and weighing again; "Hardness" by standard soap solution as usual, the results being expressed in the equivalent of calcium carbonate, while the "Permanganate" test was that of Miller. (J., Lond. Chem. Soc., 1865, p. 117 ; see also R. Angus Smith, Watts' Dictionary, v. 1029 ; Wauklyn's Water Anal., 1st Ed., 1868, p. 42 . \&c. and others), acidifying with $\mathrm{H}_{2} \mathrm{~S} \mathrm{O}_{4}$, adding 
standardized solution of permanganate, until the color held for half an hour at the ordinary temperature of the laboratory.

In addition to these, several other examinations made at irregular intervals, and at other times than those specified above might be given, but as they present no marked deviations, I will not occupy your time with them.

As a sample of similar determinations made on samples of the Croton, taken from different parts of the city at the same time, I would present the results obtained in $\Lambda_{\text {pril }}$ of last year, when the odors in the water alased suspicion that it contained some compounds dangerous to health.

\begin{tabular}{|c|c|c|c|c|c|}
\hline No. & Iocality. & Miner:u matter. & Organic \& Vol. & Total Solide. & $\begin{array}{c}\text { Oxygen absurbed } \\
\text { from } \\
\text { Permangunate. }\end{array}$ \\
\hline 1 & West 33d St. & 6.6 & 2.2 & 8.8 & 0.064 \\
\hline 2 & East 34 th St. & 6.0 & 1.5 & 7.5 & $0.060 \mathrm{~F}$ \\
\hline 5 & West $131 \mathrm{st}$ St. & 4.4 & 1.3 & 5.7 & $0.064 \mathrm{~F}$ \\
\hline 8 & East 122⿺ St. & 5.7 & trace & 5.7 & $0.66 \% 2$ \\
\hline
\end{tabular}

The samples marked $\mathrm{F}$ were clarified by subsidence or filtration before examination, as they contained varying amounts of muddy seliment, and were therefore not fair samples of the water as ordinarily used. It may be mentioned that about a pint of $\mathrm{N}_{0 .} j$ on standing half an hour in a cylinder, some $2 \frac{1}{2}$ inches in diameter, deposited a seliment of an inch in depth. When this sediment was distributed as evenly as possible through the water and a portion was examined, the results were

$\begin{array}{ccclc}\text { No. } & \text { Mincrul. } & \text { Org. and Vol. } & \text { Total. } & \begin{array}{c}\text { Oxygen from } \\ \text { Permanganate. }\end{array} \\ 2 & 75.7 & 21 & 96.70 & 0.3665 \\ 5 & 69.2 & 15.1 & 84.30 & 0.455\end{array}$

A portion of the sediment was examined separately. Shaken with ether it afforded as soluble in that menstruum, a minute proportion of vegetable wax having a slight greenish-brown tinge, probably from the presence of chlorophyll.

A small amount was obtained for analysis. The results were

Loss on ignition. $\quad 2: 3.31$

$\begin{array}{lcll}\text { Silica } & 43.61 \text { to } 51.00 \% & & \\ \text { Lime } & 0.63 & =\mathrm{CaCr}_{3} & 1.12 \% \\ \text { Magnesia } & 3.16 & =\mathrm{MgCO}_{3} & 6.64\end{array}$

Ferric and Aluminic oxides 20.92 
As to other determinations on the Croton Water, the following results are offered.

Parts per 100,000.

Dute.

August, 1874.

December, $187 \%$.

Nov. 16th, 1888.

July 11th, $18: 9$.

April 4th, 1881.

" $22 \mathrm{~d}$, "

$\begin{array}{lll}6 & 6\end{array}$

Nay $16 \mathrm{th}, 1881$.

Nov, Sth, 1881.

July 29th, 1881.

Nuv. bth, "
Free Ammonia.

0.00095

0.0010

0.0015

0.0008

0.0020

0.0016

0.001

0.002
Albummoid Ammonia.

0.0145

0.0102

0.0130

0.008

0.0110

0.0118

0.019 to 0.031 Total $\mathrm{NH}_{3}$ on very turbid samples.

The results obtained on free and albuminoid ammonia do not indicate any material alteration in the proportions of those constituents yiclaing nitrogen in those forms since the examinations began to be made. The investigation of last April shows that the quality of the water does not vary very much in different parts of the city at the same time, unless the sediment is mixed in, when the amount of nitrogen obtainable as ammonia by distillation may "arll nearly thrice the amount obtainable from the sample when failly clear.

The amounts of nitrogen in nitrates so far as they go give no indications of sewage contamination in the water.

Abont the end of last year a paper by Prof. Leeds on "Relative purity of city waters in the United States," was published in the Chemical Vews (xurv p. 265), in which the Croton water was condemned as contaminated.

The analytical results were given as follows:-

Croton, June 23d, 1881.

Free Ammonia

Albuminoid “

Oxygen required

Nitrites

Nitrates
0.0027

0.027

0.81

none

0.8325
(Results in parts per 100,000)

Chlorine

0.350

Hardness

3.30

Total Solids

11.80

Mineral Matter

5.00

Organic \& Vol.

6.80

These results I strenuously object to as misleading. 
The term "nilrates" is indefinite, and when so many chemists calculate their results to " nitrogen in nitrates," \&c. a false impression is readily created by the above statement in that regard. The "oxygen required,"I havelearned was obtained by Kubel's method -by the action of potassium permanganate on the water strongly acidified with sulphuric acid at the boiling temperature. Inasmuch as must chemists (at least in English speaking countries), use the permanganate test at ordinary temperatures, such a statement as the above, without specifying the method used, is calculated to convey a false impression of the quality of the water. Moreover the test performed in that way is open to serious objections.

Under those circumstances the chlorine in the water would affect the results, and prof Leeds himself has shown us that the reagents used invariably contain impurities which would affect the test to the prejudice of the water tested, the permanganate containing chlorine compounds, and the sulphuric acid (which is used in considerable amount) containing lower oxides of nitrogen and sulphur, so that where a line is drawn on comparatively small amounts of oxygen absorbed from permanganate, the impurities in the reagents would make a great difference in the conclusions to be drawn.

Prof. Leeds' results on 'Total Solids and Free and Albuminoid ammonia are very high, indeed higher than any results I have obtained during the past fourteen years, cxcept when-as last spring-the samples of water were so charged with sediment as to render them by no means fair samples of the Croton Water as ordinarily obtainable. The conclusion would seem to be that his sample was turbid with sediment.

With regard to other determinations they either agree with the preceding examinations, or the methods employed were different from those of which I made use, and therefore preclude a comparison between them.

In commenting on the results, Prof. Leeds remarks: "New York and all the places mentioned lower on the list receive their water from contaminated sources. The feeders which empty into Croton Lake, the principal reservoir of the New York water, pass through a settled country, with numerous tanneries, factories, \&c., along their banks. Analyses of the Croton water, made at different times during the past five years, have shown that it is to be classed among contaminated water supplies." A quotation of this statement was sent to Mr. Isaac Newton, Chief Engineer of the Croton Aqueduct Department. His reply was briefly to the effect that he 
had comparatively recently examined the Croton water-shed, and that l'rof. Leeds' assertion with regard to it was altogether erronewen.

From other sources, I have been able to ascertain, first, that with regard to the population of the water-shed: for its area of 339 square miles the population is from $1 /$ to 20,000 , or about one man to every ten acres. Permit me to quote the table given hy Mr. D. M. Greene in the $23 \mathrm{l}$ amual report of Water Commissioners of Troy for $180,1,120$.

Population of water sheds for city supplies:

City.

Rochester, N. Y.

New York, N. Y.

Albany, N. Y.

Poughkeepsic, N. Y.

Sclinectady, Cohoes, $\}$ Supply from Mo-

N. $T$.

Brooklyn, N. Y.

Buston, Mass.,

London, England,
Population per square mile.

30

60

$\pi 7$

86

103

119

229

270

Secomd.-As to industries in the Croton water-shed. But few tammerics now exist in that region for the simple reason that the most of the trecs yielding the necessary bark have been cut down, and taming is no longer profitable in that section. As regards other incustries the region contains but few factories of any kind, and those are on a small scale.

To sum up, I desire to express a most emphatic dissent from Prof. Ieeds' conclusions for the following reasons:

1. The proportion of chlorides existing in the water has not increased of late years so far as the records extend, and hence no indications of contanination by sewage or manufacturers can be asserted to exist.

2. The amounts of oxygen absorbed by permanguate test for a number of years, (serving to compare the water with itself at different times) show no changes in the quality of the Croton water. The same may be said fo' the results on Free and Alluminoid Ammonia and Organic and Volatile matter.

3. The Croton water-shed is not crowded either with population or with manufacturers as Prof Leeds seems to imagine. 
4. The health of the community is not, and has never been, such as to indicate the presence of any contamination in the water supply.

\section{COMPLETE ANALYSES OF CROTON WATER.}

RESULTS IN GRAINS PER GALLON.

\begin{tabular}{|c|c|c|c|c|c|c|c|c|c|c|}
\hline $\begin{array}{l}\text { Number } \ldots \ldots \ldots \ldots \ldots \ldots \\
\text { Analyst } \ldots \ldots \ldots \ldots \ldots \ldots\end{array}$ & \multicolumn{2}{|c|}{$\begin{array}{cc}1 & 1 \\
\text { Professor } \\
\text { J. C. Booth. }\end{array}$} & \multicolumn{4}{|c|}{ Dr. J. R. Chilton. } & \multicolumn{2}{|c|}{$\begin{array}{c}\mathbf{4} \\
\text { C.F.Chandler. }\end{array}$} & \multicolumn{2}{|c|}{ E. Waller. } \\
\hline Date............. & Eng. & 843. $\mathrm{s}$ & $\begin{array}{c}184 \\
\text { Eng. }\end{array}$ & i. $\mathrm{s}$. & $\begin{array}{l}\text { Ang } \\
\text { 16. } \\
\text { Eng. }\end{array}$ & $\begin{array}{l}\text { gust, } \\
\text { U. S.* }\end{array}$ & $\begin{array}{l}\text { Sumer } \\
1869 .\end{array}$ & $\begin{array}{l}\text { May, } \\
1872 .\end{array}$ & $\begin{array}{l}\text { May } \\
1879 .\end{array}$ & $\begin{array}{l}\text { Noy. } \\
1881 \text {. }\end{array}$ \\
\hline $\begin{array}{l}\text { Sodium chloride } . . . . . . \\
\text { Calcium sulphate........ } \\
\text { Alkaline chlorides...... }\end{array}$ & 0,193 & 0.161 & 0.44 & $\begin{array}{l}0.367 \\
\cdots \cdots \\
\cdots\end{array}$ & $\begin{array}{l}4.404 \\
0.353 \\
\ldots\end{array}$ & $\begin{array}{l}0.335 \\
0.294\end{array}$ & $\begin{array}{l}0.402 \\
0.158\end{array}$ & $\begin{array}{l}0.284 \\
0.024\end{array}$ & $\begin{array}{ll}0 & 20.5 \\
0.723\end{array}$ & $\begin{array}{l}0.20 \% \\
\cdots \cdots\end{array}$ \\
\hline $\begin{array}{l}\text { Potassium sulphate...... } \\
\text { Sodium sulphate........ }\end{array}$ & & & & & $\cdots \cdots$ & $\cdots \cdots$ & $\begin{array}{l}0.179 \\
0.260\end{array}$ & $\begin{array}{l}0.205 \\
0.024\end{array}$ & $\begin{array}{l}0.188 \\
0.200\end{array}$ & 0201 \\
\hline Akaline & 0.828 & 0.690 & 0.90 & & 0.270 & 0.225 & & ....... & $\cdots \cdots$ & 0.054 \\
\hline $\begin{array}{l}\text { Magn } \\
\text { Calcil }\end{array}$ & & & 0.84 & 0.750 & $\begin{array}{l}0.147 \\
0.101\end{array}$ & $\begin{array}{l}0.122 \\
0.087\end{array}$ & & $\cdots \cdots \cdots$ & & ..... \\
\hline Magnesium & 0.939 & 0.782 & 1.52 & $0 . \tilde{r} 00$ & 0.390 & 0.325 & $(1,10 \dddot{1})$ & $(0.7 \% 0)$ & 0.918 & 0.685 \\
\hline & 2.293 & 1.910 & $\cdots$ & 1.266 & 0.836 & 0.696 & $(1.648)$ & $(1.439)$ & 1.650 & $1.3 ! 9$ \\
\hline Calcium bicarbonate... & & & & $\cdots \cdots$ & $\cdots \cdots$ & $\cdots \cdots \cdots$ & $\begin{array}{l}1.913 \\
2.670\end{array}$ & 2.331 & & \\
\hline Ferric \& aluminic oxides & 0.110 & 0.092 & & & & & trace & 0.058 & 0.175 & 0.045 \\
\hline Silica. . & 0.359 & 0.299 & 0.46 & 0.383 & 0.170 & 0.142 & 0.621 & 0.222 & 0.274 & 0.210 \\
\hline Organic and volatile.... & 0.276 & 0.240 & & $\cdots \cdots$ & 0.916 & 0.763 & 0670 & 0.874 & 0.560 & 0.233 \\
\hline Total solids. & & & & & 3.590 & 2.990 & $6.8 \div 3$ & 5,360 & & \\
\hline $\begin{array}{l}\text { Solids by evaporation... } \\
\text { Cblorine.............. }\end{array}$ & 4.998 & $\begin{array}{l}4.174 \\
\ldots \ldots\end{array}$ & 4.16 & $\begin{array}{c}3.466 \\
\cdots \quad \cdots\end{array}$ & 3.705 & $\begin{array}{l}3.087 \\
0.296\end{array}$ & $\begin{array}{l}4.780 \\
0.243\end{array}$ & $\begin{array}{l}3.849 \\
0.1 \% 2\end{array}$ & $\begin{array}{l}4.893 \\
0.124\end{array}$ & $\begin{array}{l}3.168 \\
0.124\end{array}$ \\
\hline
\end{tabular}

ABOVE RESULTS GIVEN IN PARTS PER HUNDRED THOUSAND.

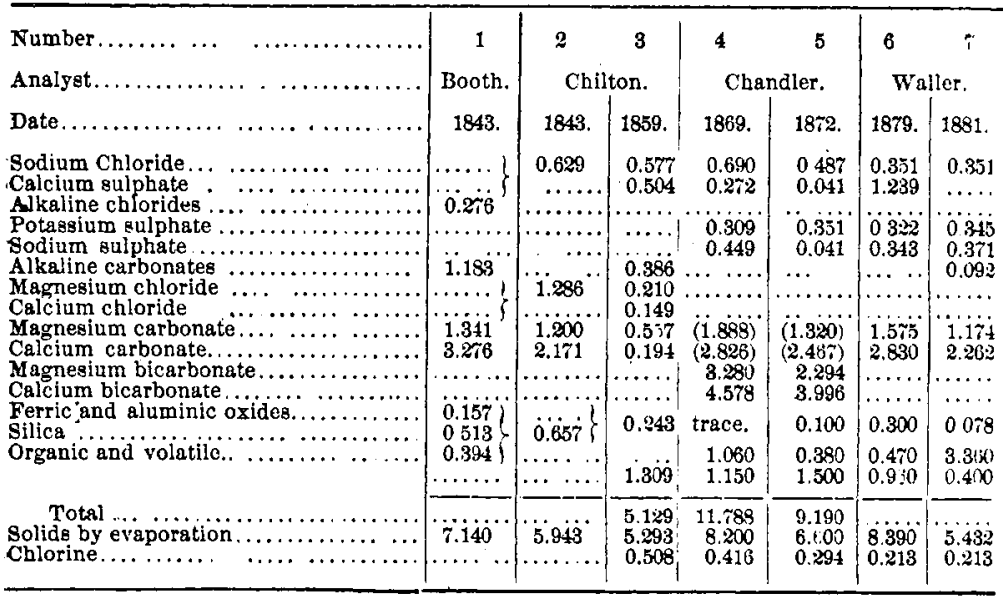

Nos. 1 and 2. Illustrations of the Croton Aqueduct. F. B. Tower. N. Y., 1843, p. 135,

No. 3. Keport of Water Colnmiseioners of Albany for $1865, \mathrm{p} .50$.

Nos. 4 and 5 . Report of Board of Health for $18 \pi 1$, New York, p. 371

No. 6. Report on Croton Water, New York, 1881, p. 45.

* U. S. gallon of 231 cubic inches $(58,318$ grains). 